\title{
Analysis of the effect of health insurance on health care utilization in Rwanda
}

\section{Roger Muremyi ${ }^{1, *}$, Dominique Haughton ${ }^{2}$, François Niragire $^{3}$, Ignace Kabano ${ }^{4}$}

${ }^{1}$ African Centre of Excellence in Data Science, University of Rwanda, Kigali, Rwanda; muremyiroger@gmail.com

${ }^{2}$ Mathematical Sciences and Global Studies, Bentley University, Boston, United States of America, Université Paris 1 Panthéon Sorbonne (SAMM), Université Toulouse 1 (TSE-R); DHAUGHTON@ bentley.edu

3 Department of Applied Statistics, University of Rwanda, Kigali, Rwanda; fniragire@gmail.com

4 African Centre of Excellence in Data Science, University of Rwanda, Kigali, Rwanda;muremyiroger@gmail.com

\section{*Corresponding author:muremyiroger@gmail.com}

\begin{abstract}
In Rwanda, more than $90 \%$ of the population is insured for health care. Despite the comprehensiveness of health insurance coverage in Rwanda, some health services at partner institutions are not available, causing insured patients to pay unintended cost. We aimed to analyze the effect of health insurance on health care utilization and factors associated with the use of health care services in Rwanda. This is an analysis of secondary data from the Rwanda integrated living condition survey 2016-2017. The survey gathered data from 14580 households, and decision tree and multilevel logistic regression models were applied. Among 14580 households only (20\%) used health services. Heads of households aged between [56-65] years (AOR=1.28, 95\% CI:1.02-1.61), aged between [66-75] years (AOR=1.52, 95\% CI: 1.193-1.947), aged over 76 years (AOR=1.48, 95\% CI:1.137-1.947), households with health insurance (AOR=4.57, 95\% CI: 3.97-5.27) displayed a significant increase in the use of health services. This study shows evidence of the effect of health insurance on health care utilization in Rwanda: a significant increase of 4.57 times greater adjusted odds of using health services compared to those not insured. The findings from our research will guide policymakers and provide useful insights within the Rwanda context as well as for other countries that are considering moving towards universal health coverage through similar models.
\end{abstract}

Keywords: health care, insurance, decision tree, Rwanda

\section{Introduction}


Access to health care is an important determinant in assessing equity in health care utilization. However, in developing countries, health care utilization is not influenced only by demand constraints but also supply constraints which are determined solely by the ability to pay rather than the need for health care services [1,2]. Moreover, this situation can impose heavy financial burdens on individuals as well as households and in certain instances can impoverish them or lead to a financial catastrophe [3]. Finally, inequities in health care utilization have been documented, and those who need health care are not receiving what might be considered a fair share of benefits [4,5]. In Rwanda, it was in the 1960s that community-based health insurance systems, like the association Muvandimwe de Kibungo (1966) and the association Umubano mubantu de Butare (1975) started to be constituted [6,7]. Moreover, these community-based health insurance initiatives were further developed only since the reintroduction of the payment policy in $1996[6,7]$. The development of community-based health insurance initiatives in the form of modern mutual health insurance has been on the increase during the past five years [7,8,9]. Moreover, the geographical coverage of mutual health insurance was also extended: whereas initially in 1999 these mutual health insurances were mainly developed in the four provinces of the country, they have since August 2004 been established in virtually all eleven provinces of the country, as well as in the city of Kigali [8].

Upon independence in 1952, Rwanda inherited a free of charge health care policy which was revealed later to be unrealistic, ineffective and unsustainable. It was therefore abandoned. Apart from insurance for occupational disease and injuries covered by Caisse Social du Rwanda (CSR) for formal sector employees, the abandonment of the system created a total vacuum, leaving the entire population exposed to diverse risk related to health without any insurance coverage $[10,11]$. However, this situation has changed dramatically with the emergence and extension of Community Based Health Insurance (CBHI) system [12]. At the end of 2008, Rwanda had achieved an impressive health insurance coverage of 92\% of its population [13]. In addition to this, the national Community Based Health Insurance coverage rate was estimated at $85 \%$, with other insurance schemes covering an estimated $4 \%$ of the population [13]. Therefore, universal access to equitable and affordable quality health services for all Rwandans is the overall aim of the Government of Rwanda's (GoR) Health Sector Policy [14]. The priorities set forth in the Health Sector Policy are based on the development goals laid out in the Economic Development and Poverty Reduction Strategy and Rwanda's Vision 2020 [15]. The Mutuelles de Santé/Community-Based Health Insurance (CBHI) scheme was 
developed to meet the needs of Rwandans outside of the formal sector, where access to and utilization of healthcare services had been historically very low [15]. Beginning with pilots in 1999, and established as national policy in 2004, Rwanda quickly scaled Community-Based Health Insurance (CBHI) across the country. Membership grew to $91 \%$ of the target population by 2010-11 [16]. Enrollment decreased in recent years, with a June 2015 estimate of $75 \%$ coverage, among those eligible for the scheme [16].

Nowadays in Rwanda, health care insurance is highly successful because of the high effort put into it. The new system was implemented, where people paying their contributions according to their income and their financial capacity; this new system use data from UBUDEHE categories [17]. Category one persons have their contribution paid by government, categories two and three pay 3000frws and the fourth category pays 7000frws. This policy has increased the potential of mutual health insurance, so that the majority of the population of Rwanda could benefit from it [18].

Over the years, Rwanda has seen an important increase in total health expenditure (THE) per capita, increasing from US\$ 34 in 2006 to 840 in 2014 [19]. Public sources accounted for the majority of total health expenditure, and households contributed for $26 \%$ of total health expenditure through out of pocket health expenditure (OOP) [19]. In its efforts to improve access, the country has developed a comprehensive health sector strategic plan $[19,20]$. A major focus of this plan is the expansion of health insurance to the informal sector through Mutual Health Insurance [20]. Building on the experience of earlier pilots, the government supported start-up initiatives and Mutual Health Insurance schemes were created between 2000 and 2003 $[19,20]$. Moreover, population coverage increased continuously during this period and was estimated to reach $51.5 \%$ in 2004 [20]. Mutual Health Insurance (MHI) was further scaled up in 2005 with the support of external funding [21]. The aim of this expansion was to rapidly increase membership of vulnerable groups through premium subsidies and strengthen administrative capacities and pooling mechanisms [22].

By 2007, around $74 \%$ of the population had some form of health insurance cover. Furthermore, in 2008, a formal legal framework for Mutual Health Insurance was created with the adoption of a law on mutual health insurance [23] and this set a new milestone towards universal coverage by making health insurance compulsory. Even though there is facilitation for getting health care utilization for those who have health insurance in Rwanda, there are still problems for some people who did not get all contribution at the same 
time. This is a serious problem; consider for example a family of nine persons in the second ubudehe category [23]. This family would need to pay a premium for each of the nine members for any of the members to be covered [23]. This is problematic because once you get ill or one of your family gets ill, you cannot receive health care as an insured patient and you have to get medical treatment by paying $100 \%$ of the cost as a private patient, unless all family members have paid a premium and this cause mal-treatment in hospitals [23]

The findings of other researchers from developing countries assessed the impact of health insurance on health services utilization and health outcomes in Vietnam (G.Ewmmanuel Gwindon, (2014)) [26]; their findings showed that for both poor and students, health insurance increased the use of inpatients services but it was not the case for outpatients services. The same study found that for young children, health insurance increased the use of outpatients services but it was not the case for inpatients services [26]. A study with some similarities was conducted by Agatuba et al., (2012) on the impact of health insurance on health care utilization and out of pocket payments in South Africa and found that the use of health insurance coverage increases the use of private of health services as was expected and there was no significant effect on the use of public services. The same study showed that the use of health insurance did not contribute to the reduction of out of pocket payments compared to those without health insurance coverage[27]. Furthermore, Thuong NTT.et.al (2020) [25], conducted a study on the impact of health insurance on healthcare utilization patterns in Vietnam. Their results indicated that the use of health insurance increased the number of outpatients visits; the enrollment was varying from 0.87 to 1.29 and their findings suggested that participation in health insurance had the most effect on the use of healthcare services at district hospitals. [25]. Finally, referring also to the previous studies in developed countries, on the impact of massive expansion of health insurance program on health care utilization and health outcomes in Japan, Manning et al. (1987) [17] showed a substantial increase in health care utilization, which were much larger than what would be implied by the individual-level effect estimated[17]. Existing research in Rwanda, conducted by Ruhara et al. (2016) [22] on the role of economic factors in the choice of medical providers indicated that health insurance was an important factor in the choice of health facilities and the user fees were major financial barriers to health care access in Rwanda. The same study suggests that as household income increases, patients shift from public to private health facilities where quality was assumed to be higher than for public health providers [28]. Previous research in Rwanda has talked about various aspects of the effect of health insurance on health care utilization in Rwanda focusing 
much on mutual health insurance or Community Based Health Insurance(CBHI), including helping to understand the determinants of enrolment for mutual health insurance [28]. However, some studies also reveal that out-of-pocket health payment is still powerful and penetratingly in Rwanda despite the presence of Mutual health insurance (Lu C et al.2012; Roger Muremyi et al.2020; Médard Nyandekwe et al., 2020; Ruhara et al. 2016) $[22,29,30,34,35,36]$. To our knowledge no study on the effect of health insurance on health care utilization in Rwanda has used decision tree models to classify districts of Rwanda on the use of health services by households based on the same characteristics of the households.

This paper contributes to the literature in analyzing the effect of health insurance on health care utilization in Rwanda at the household level and complements existing research by analyzing the covariates that influence most the use of health care services in Rwanda.

\section{Material and Methods}

\subsection{Study setting}

Rwanda has a gross national per capita income of 2155 USD [31] and is a landlocked sub-Saharan African (SSA) country. Rwanda is ranked 160 th out of 189 countries on the 2019 Human development index [31]. From 2000 up to 2019, the percentage of people living in poverty dropped from 59\% to approximately $46 \%$ in 2010 and then to $39.1 \%$ in 2019. [32]. Currently, $17.6 \%$ of the population of Rwanda lives in urban areas. [32]. The country is bordered by the Democratic Republic of Congo (DRC) to the west, Uganda to the north, Tanzania to the east and Burundi to the south [32]. Its administration is composed by Kigali City nd four provinces, with 30 districts. Health care services in Rwanda are controlled by the National Health Insurance Council (NHIC) that has the mandate of advising, supervising health insurance activities and setting the prices for health services as is stipulated in the health insurance law issued in 2016 [33].

\subsection{Data Source}

This study used the data from the Rwanda household living standard survey conducted from 2016-1017 (EICV 5). The survey was conducted by the National Institute of Statistics of Rwanda (NISR) [34]. This nationally representative survey gathered data from 14580 households and 64314 individuals, including head of households who received health services with or without health insurance. [33, 34]. Moreover, in 
this paper data related to consumption expenditure on food and out-of-pocket health expenditures including: consultation; laboratory tests; hospitalization; medication, socio-economic indicators and insurance status, self-reported health need and utilization of health services at household level were extracted. Finally, we have explored the relationship between health insurance and utilization of health care among insured and non-insured heads of households. A logistic regression model will be constructed as well as a decision tree model to assess the interaction between covariates[33, 34]

\subsection{Variables and their measurements}

\subsubsection{Dependent variable}

In line with the objective of this study to analyze the effect of health insurance on health care utilization in Rwanda, we defined whether the head of household received health services in the last four weeks as the outcome. Whether the head of household received medical care or not will be used as dependent variable and it will take two values such as $\mathrm{Y}=(0,1)$, where the head of households received medical care for $\mathrm{Y}=1$, and for $\mathrm{Y}=0$. In this research paper a binomial logistic regression model has been used to estimate the probability of health care demand of the head of household and decision tree model for classification of districts on the use of health services by the head of households. This dependent variable was chosen based on previous studies by (Agatuba et.al, (2012); G.Ewmmanuel Gwindon, (2014); Thuong NTT., (2020)) and their recommendations [25,26,27].

\subsubsection{Covariates}

From the analytical framework of the previous studies on the effect of health insurance on health care utilization in developing countries with the same similarities as Rwanda and the existing literature (Agatuba et.al, (2012); G.Ewmmanuel Gwindon, (2014); Thuong NTT., (2020), Nakovics et.al, (2020); Mulaga AN.et.al, (2021)) [25,26,27, 29, 35] we selected covariates based on socioeconomics status, demographics, education level, region. Ages were divided into five groups, education level of the head of households supposing that better educated head of households are more likely to make their own decisions on their 
dependents' health services. We also include household expenditure quintiles [35], sex of the head of household, households size, region, household insurance status, district, occupation status of the head of household, marital status of the head of household, head of household insurance status, out of pocket health expenditures of the household, household per capta expenditures. Finally, in this study we performed first the decision tree model for the purpose of classifying the districts based on the use of health services at the household level. Those classes were then used in a logistic regression analysis to assess the interactions between districts and other covariates on the use of health services.

\subsection{Decision tree model}

Decision Trees are a non-parametric supervised learning method used for both classification and regression tasks [31].

\section{Results}

Table 1: Variables description of socio-economic and demographics of sampled households ( $\mathrm{n}=14580$ households)

\begin{tabular}{|l|r|l|l|l|r|}
\hline & & & & & \\
Variable & Observations & or & & \\
proportion & Std. Dev. & Min & Max \\
\hline Head of household received & 14580 & .206 & .405 & 0 & 1 \\
\hline
\end{tabular}




\begin{tabular}{|c|c|c|c|c|c|}
\hline \multicolumn{6}{|l|}{ health care in last four weeks } \\
\hline \multicolumn{6}{|l|}{$\begin{array}{l}\text { Age_group of the head of } \\
\text { households }\end{array}$} \\
\hline $\begin{array}{l}\text { between [14-24] years old } \\
\text { (referance level) }\end{array}$ & 14580 & .049 & .216 & 0 & 1 \\
\hline between [25-35] years old & 14580 & .290 & .453 & 0 & 1 \\
\hline between [36-45] years old & 14580 & .225 & .418 & 0 & 1 \\
\hline between [46-55]years old & 14580 & .178 & .382 & 0 & 1 \\
\hline between [56-65] years old & 14580 & .141 & .348 & 0 & 1 \\
\hline between [65-75] years old & 14580 & .069 & .253 & 0 & 1 \\
\hline between [76-109] years old & 14580 & .045 & .208 & 0 & 1 \\
\hline $\begin{array}{l}\text { head of household with health } \\
\text { insurance }\end{array}$ & 14580 & .752 & .431 & 0 & 1 \\
\hline Per capita expenditure & 14580 & 2.242 & 3.786 . & .413 & 1297.35 \\
\hline \multicolumn{6}{|l|}{ Sex of the head of household } \\
\hline Male (referance level) & 14580 & .744 & .436 & 0 & 1 \\
\hline Female & 14580 & .255 & .436 & 0 & 1 \\
\hline \multicolumn{6}{|l|}{ quintile } \\
\hline Quintile1(referance level) & 14580 & .166 & .372 & 0 & 1 \\
\hline Quintile2 & 14580 & .182 & .385 & 0 & 1 \\
\hline Quintile3 & 14580 & .196 & .397 & 0 & 1 \\
\hline Quintile4 & 14580 & .211 & .408 & 0 & 1 \\
\hline Quintile5 & 14580 & .243 & .429 & 0 & 1 \\
\hline Out of pocket expenditure & 14580 & 20185 & 71186.58 & 0 & 4200000 \\
\hline $\begin{array}{l}\text { Districts group1 vs health } \\
\text { insurance }\end{array}$ & 14580 & .414 & .492 & 0 & 1 \\
\hline $\begin{array}{l}\text { Districts group2 vs health } \\
\text { insurance }\end{array}$ & 14580 & .169 & .375 & 0 & 1 \\
\hline
\end{tabular}




\begin{tabular}{|lr|r|r|r|r|r|}
$\begin{array}{l}\text { Districts group3 vs health } \\
\text { insurance }\end{array}$ & 14580 & .255 & .435 & 0 & 1 \\
\hline $\begin{array}{l}\text { Districts group4 vs health } \\
\text { insurance }\end{array}$ & 14580 & .077 & .268 & 0 & 1 \\
\hline $\begin{array}{l}\text { Districts group5 vs health } \\
\text { insurance }\end{array}$ & 14580 & .0979 & .296 & 0 & 1 \\
\hline $\begin{array}{l}\text { Districts group } 6 \text { vs health } \\
\text { insurance }\end{array}$ & 14580 & .131 & & .338 & & \\
\hline
\end{tabular}

Table 1 describes the variables used in this study. Most of them were socioeconomics and demographics characteristics of the households selected in this research. It shows that around $29 \%$ of the head of households were 25 to 35 years old and a large number of the heads of households were male with percentages of $75 \%$ of the head of households. About $75 \%$ of the households had medical insurance. A larger proportion (41\%) of the households with medical insurance was seen in group one composed by the districts of Burera, Gakenke, Gasabo, Gatsibo, Gicumbi, Kamonyi, Kicukiro, Muhanga, Musanze, Ngororero, Nyabihu, Nyagatare, Nyarugenge, Rubavu, Rulindo, Rutsiro and the following proportion (16\%) of households with medical insurance was seen in group 2 in the districts of Gisagara, Karongi, Kirehe, Nyaruguru, Ruhango, Rusizi, Rwamagana and $25 \%$ of households with medical insurance was seen in districts group 3 of Gicumbi, Kicukiro, Musanze, Ngororero, Nyabihu, Nyagatare, Nyarugenge,Rubavu, Rulindo, Rutsiro. A smaller proportion $(7 \%)$ of households with medical insurance was seen in group 4 in the districts of Musanze, Rubavu, Rulindo, Rutsiro. Finally, the yearly average of the out of pocket health expenditure was 20185 Rwandan Francs.

Fig1. Decision tree model for classifications of districts based on the use of health services 


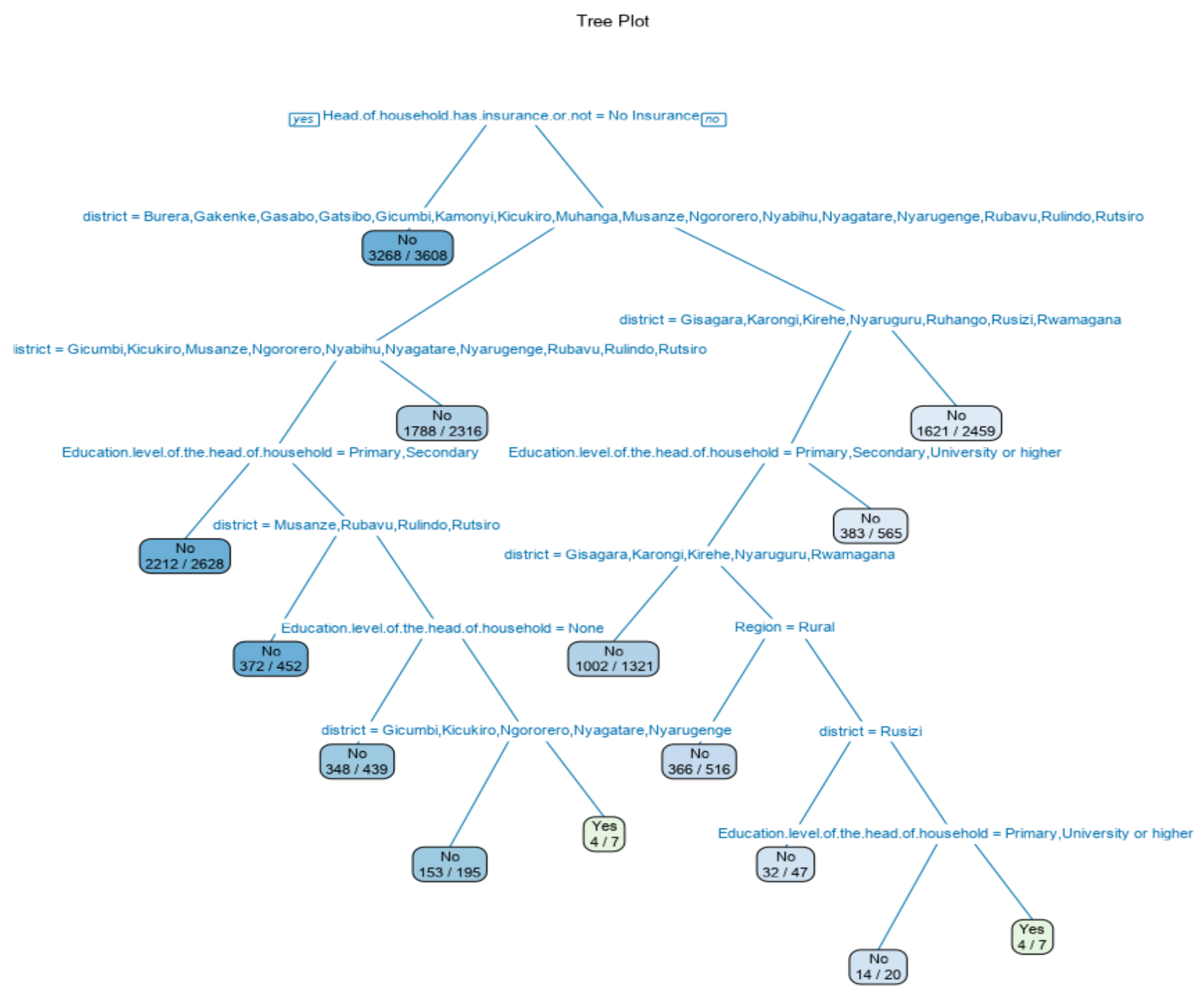

This

decision tree model was performed to capture the interactions between features such as head of household education level, region and district location of the selected households. More importantly, the model indicated the classification of the districts based on the similarities or differences between districts on the use of health care services by households. Moreover, this decision tree classified the districts into seven groups such as group one with the districts of [Burera, Gakenke, Gasabo, Gatsibo, Gicumbi, Kamonyi, Kicukiro, Muhanga, Musanze, Ngororero, Nyabihu, Nyagatare, Nyarugenge, Rubavu, Rulindo, Rutsiro]; group two with districts of [Gisagara, Karongi, Kirehe, Nyaruguru, Ruhango, Rusizi, Rwamagana]; group three [Gikumbi, Kicukiro, musanze, Ngororero, Nyabihu, Nyagatare,Nyarugenge, Rubavu, Rulindo, Rutsiro ]; group four [ Musanze, Rubavu, Rulindo, Rutsiro]; group five[Gisagara, Karongi, Kirehe, Nyaruguru, Rwamagana]; group 
six[Gicumbi, Kicukiro, Ngororero, Nyagatare, Nyarugenge], group seven is composed only one district of Rusizi.

Table 2: Logistic regresion model for probability of using medical services by head of household.

\begin{tabular}{|c|c|c|c|c|c|c|}
\hline $\begin{array}{l}\text { Head of household } \\
\text { received health care in last } \\
\text { four weeks }\end{array}$ & Odds Ratio & Std. Err. & $\mathrm{z}$ & $\mathrm{P}>\mathrm{Z}$ & {$[95 \%$ Conf. } & Interval] \\
\hline \multicolumn{7}{|l|}{$\begin{array}{l}\text { Age groups of the head of } \\
\text { households }\end{array}$} \\
\hline between $25-35$ years & .895 & .098 & -1.01 & 0.314 & .721 & 1.110 \\
\hline between $36-45$ years & .942 & .106 & -0.53 & 0.599 & .754 & 1.176 \\
\hline between $46-55$ years & 1.096 & .125 & 0.80 & 0.423 & .875 & 1.372 \\
\hline between $56-65$ years & 1.285 & .148 & 2.17 & 0.030 & 1.024 & 1.611 \\
\hline between $66-75$ years & 1.524 . & .190 & 3.37 & 0.001 & 1.193 & 1.947 \\
\hline over 76 years & 1.482 & .2001 & 2.92 & 0.004 & 1.137 & 1.931 \\
\hline $\begin{array}{l}\text { head of household with } \\
\text { health insurance }\end{array}$ & 4.575 & .330 & 21.02 & 0.000 & 3.970 & 5.272 \\
\hline Per capita expenditure & .996 & .00089 & -3.76 & 0.000 & .994 & .998 \\
\hline \multicolumn{7}{|l|}{$\begin{array}{l}\text { Sex of the head of } \\
\text { household }\end{array}$} \\
\hline Female & 1.458 & .072 & 7.61 & 0.000 & 1.323 & 1.607 \\
\hline \multicolumn{7}{|l|}{ quintile } \\
\hline Quintile2 & 1.112 & .085 & 1.40 & 0.163 & .957 & 1.293 \\
\hline Quintile3 & 1.203 & .089 & 2.49 & 0.013 & 1.039 & 1.392 \\
\hline Quintile4 & 1.327 & .097 & 3.87 & 0.000 & 1.150 & 1.532 \\
\hline Quintile5 & 1.315 & .102 & 3.53 & 0.000 & 1.129 & 1.531 \\
\hline $\begin{array}{l}\text { Out of pocket health } \\
\text { expenditures }\end{array}$ & 1.000 & $4.32 \mathrm{e}-07$ & 10.49 & 0.000 & 1.000 .4 & 1.000 .05 \\
\hline $\begin{array}{llr}\text { Interaction } & \text { of } & \text { Group1 } \\
\text { districts } & \text { with health } \\
\text { insurance } & & \end{array}$ & .573 & .03 & -8.35 & 0.000 & .503 & .653 \\
\hline $\begin{array}{llr}\text { Interaction } & \text { of } & \text { Group2 } \\
\text { districts } & \text { with } & \text { health } \\
\text { insurance } & & \end{array}$ & .758 & .061 & -3.38 & 0.001 & .646 & .890 \\
\hline $\begin{array}{llr}\text { Interaction } & \text { of } \text { Group3 } \\
\text { districts } & \text { with health } \\
\text { insurance } & & \end{array}$ & .669 & .078 & -3.42 & 0.001 & .531 & .842 \\
\hline $\begin{array}{llr}\text { Interaction } & \text { of } & \text { Group4 } \\
\text { districts } & \text { with } & \text { health } \\
\text { insurance } & & \end{array}$ & 1.115 & .147 & 0.83 & 0.408 & .860 & 1.446 \\
\hline
\end{tabular}




\begin{tabular}{|c|c|c|c|c|c|c|}
\hline $\begin{array}{lll}\text { Interaction of } & \text { Group5 } \\
\text { districts } & \text { with health } \\
\text { insurance } & & \end{array}$ & .945 & .087 & -0.61 & 0.544 & .789 & 1.133 \\
\hline $\begin{array}{llr}\text { Interaction } & \text { of } & \text { Group6 } \\
\text { districts } & \text { with health } \\
\text { insurance } & & \end{array}$ & 1.032 & .127 & 0.26 & 0.798 & .810 & 1.314 \\
\hline Constant & .074 & .009 & -20.79 & 0.000 & .058 & .095 \\
\hline
\end{tabular}

Table 2 indicates the logistic regression model where the odds ratio with $\mathrm{p}$ values less than 0.05 were used to determine whether a change in a predictor variable makes the use of health care services more likely ceteris paribus.

Fig2: Main health insurance carried out by the head of the household

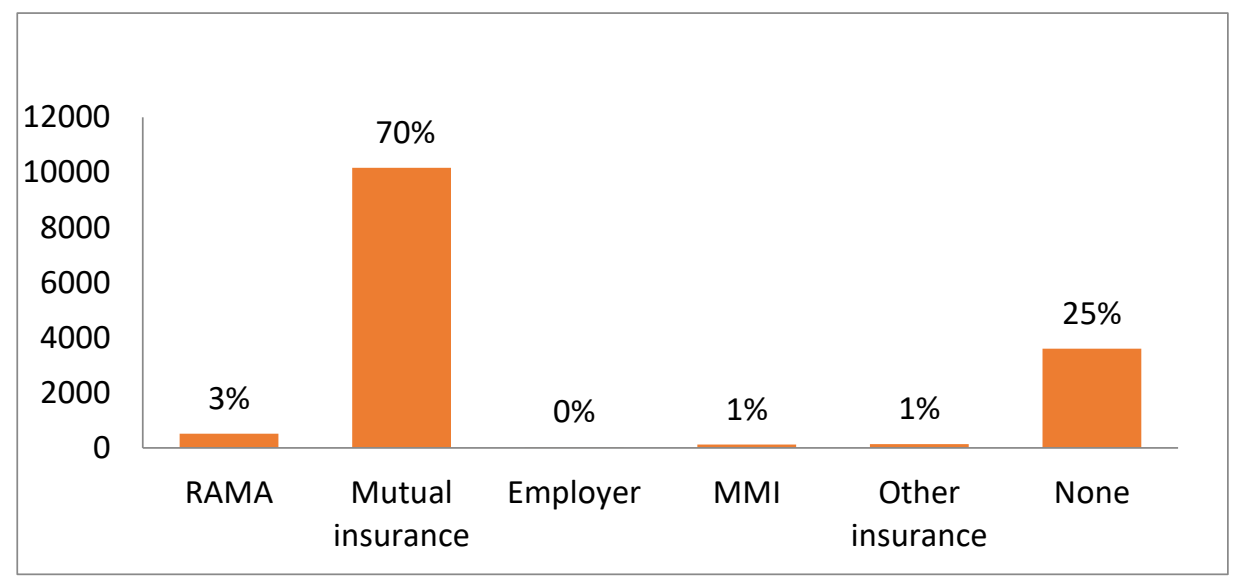

The high rate of health insurance carried out by the head of the household was found in mutual health insurance and covering $70 \%$ of all respondents.

\section{Discussion}

This research aimed at examining the effect of the health insurance on health care utilization in Rwanda.

The findings from our study showed a significant age effect. For heads of households aged between [56-65] years old ( $\mathrm{AOR}=1.28,95 \% \mathrm{CI}: 1.02-1.61)$ a significant increase were observed, for those aged between 
[66-75] years old (AOR=1.52, 95\% CI: 1.193-1947) a significant increase were observed, for those aged over 76 years old $\quad(A O R=1.48,95 \%$ CI:1.137-1.947) a significant increase were observed $(\mathrm{p}<0.005)$.

Households with health insurance ( $\mathrm{AOR}=4.57,95 \% \mathrm{CI}: 3.97-5.27)$ displayed a significantly higher use of health services compared to those with no health insurance, households headed by female(AOR=1.45, 95\% CI: 1.32-1.60) displayed a higher use of health services compared to households headed by males, for quintile $3(\mathrm{AOR}=1.20,95 \% \mathrm{CI}: 1.039-1.39)$, for quintile $4(\mathrm{AOR}=1.32,95 \% \mathrm{CI}: 1.150-1.152)$, for quintile 5(AOR $=1.131,95 \%$ CI: 1.129-1.151) increased the use of health services compared to the poorest income quintile, out of pocket health expenditure (AOR=1,95\% CI: 1.000004-1.000005) increased the adjusted odds of using health services and the per capita expenditure (AOR=0.99, 95\% CI: 0.994-0.998) decreased the use of health services.

Households of group district 1 with health insurance (AOR=0.57, 95\% CI:0.50-0.65) had a 57\% less odds of using health services compared to households located in Rusizi district, group district 2 with health insurance (AOR=0.75, 95\% CI:0.64-0.89) had a 75\% less odds of using health services compared to households located in Rusizi district, group district 3 with health insurance (AOR=0.69, 95\% CI:0.53-0.84) had a 69\% less odds of using health services compared to households located in Rusizi district.

Our results proved that interactions between group one of the districts of [Burera, Gakenke, Gasabo, Gatsibo, Gicumbi, Kamonyi, Kicukiro, Muhanga, Musanze, Ngororero, Nyabihu, Nyagatare, Nyarugenge, Rubavu, Rulindo, Rutsiro] and households with medical insurance presented a significant statistical differences on the use of health care services, there was a decrease in the use of health services at the proportion of $57 \%$ which means that districts in group one used health services less likely than districts of group 7 as reference group that was Rusizi; group two with districts of [Gisagara, Karongi, Kirehe, Nyaruguru, Ruhango, Rusizi, Rwamagana] and households with medical insurance presented a significant statistical differences on the use of health services with negative coefficient which indicated the less likely (75\%) on the use of health services compared to the households located in Rusizi as reference district. While, households for group three [Gikumbi, Kicukiro, musanze, Ngororero, Nyabihu, Nyagatare,Nyarugenge, Rubavu, Rulindo, Rutsiro ] and houesholds with medical insurance used health services less likely at the proportion of $69 \%$ compared to those located in Rusizi Districts. Finally, households located in group 4, group 5 and group 6 with health insurance did not have an effect on health insurance on health care utilization in Rwanda. This study also showed that there was a signficant statistical differences among households with health insurance on the use of health 
services and there was a significant increase of 4.57 times greater adjusted odds of using health services compared to those with no health insurance of the use of health services at $95 \%$, this increase provide an evidence that more people with medical insurance received health services when there were in need.

The purpose of this research paper was to examine the effect of health insurance on health care utilization in Rwanda. The summary statistics from Table 1 showed that on average there were four household members in a house and the percentages of households with health insurance were $75.25 \%$ and about $24.75 \%$ were no health insurance. For the locations of the households $83 \%$ were in rural area while $17 \%$ of the households were in the urban area. For educational level $61.24 \%$ of the head of household completed at most primary studies and the head of households received medical consultation in the over last four weeks were in 3015 households that was $20.68 \%$ of the head of households received health care services while 11,565 head of households did not receive health care services that was $79.32 \%$ of the households considered in this study. The yearly out of pocket health expenditures on the average was 20185Rwandan francs and the findings showed that age of head of households has increased the use of health care services. In fact, health insurance has a higher effect on health care utilization. Moreover, per capita expenditures influence affect negatively the use of health care services due to its change at household level.

The high rate of health insurance carried out by the head of the household was found in Mutual health insurance and covering $70 \%$ of all respondents. However, a big number of the head of households who went for medical consultation was found in sickness where was around $90.18 \%$ of all participants.

Based on the results from Fig 1 at the root node of this decision tree we had 14580 households as sample of our study, 3015 households received health care service by the head of households, that was $20 \%$, and $80 \%$ did not receive health services. Health insurance was considered as the primary split and was used to split other remaining nodes. The districts of Burera, Gakenke, Gasabo, Gatsibo, Gicumbi, Kamonyi, Kicukiro, Muhanga, Musanze, Ngororero, Nyabihu, Nyagatare, Nyarugenge, Rubavu, Rulindo, Rutsiro, had 6037 heads of households; only 1161 heads of households received health service, that was $20 \%$ of 6037 head of households and $80 \%$ did not receive health services.

For districts of Gikumbi, Kicukiro, musanze, Ngororero, Nyabihu, Nyagatare,Nyarugenge, Rubavu, Rulindo, Rutsiro, among 3721 households only 633 received health services, that was $17 \%$ of 3721 heads of households and $83 \%$ of 3721 heads of households did not receive health services. 
The heads of households who completed at least primary and secondary studies were 2628; among them 416 received health services while those who completed at least university or higher and no level of education were 1093 of households; among them 217 head of households received health services.

The districts Musanze, Rubavu, Rulindo, Rutsiro were classified in one group, 452 heads of households only 80 of whom received health services.

For Gicumbi, Kicukiro, Ngororero, Nyabihu, Nyagatare, Nyarugenge, 641 heads of households; among them 137 received health services and considering the education level of the head of households, the households with no education were 439 heads of households among whom only 91 households received health services and those with at least the university level were 202 head of households, among whom 46 head of households received health services. For Gicumbi, Kicukiro, Ngororero, Nyagatare, Nyarugenge, 195 head of households only 42 received health care services that was $22 \%$ of 195 head of households and in Nyabihu district 7 households were considered and 3 households received health care services, for the group of districst of Burera, Gakenke, Gatsibo, Kamonyi, Muhanga, 2316 head of households only 528 received health care services. For Bugesera, Gisagara, Huye, Karongi, Kayonza, Kirehe, Ngoma, Nyamagabe, Nyamasheke, Nyanza, Nyaruguru, Ruhango, Rusizi, Rwamagana were classified together and there were 4935 households among them 1514 received health care services, for Gisagara, Karongi, Kirehe, Nyaruguru,Ruhango, Rusizi, Rwamagana 2476 head of households were considered and 676 only received health care services. For educational level of the head of households who completed at least primary, secondary, university were1911 head of households among them 494 received health services. For Gisagara, Karongi, Kirehe, Nyaruguru, Rwamagana 1321 head of households only 319 head of households received health care services. For Ruhango and Rusizi 590 head of households only 175 received health care services and 516 were classified in the rural area only 150 received health care services and 74 were located in the urban area only 25 received health care services, for head of households located in Rusizi district 47 head of households only 15 received health care services and those located in Ruhango 27 head of households only 10 head of households received health services. Finally,Bugesera, Huye, Kayonza, Ngoma, Nyamagabe, Nyamasheke, Nyanza 2459 head of households only 838 head of households received health care services and the proportion of correct predictions in the data were $79.3 \%$ with harmonic mean of recall and precision were $88.5 \%$, Precision was $79.4 \%$ and proportion of values actually positive, that were predicted positive by $99.9 \%$.

\section{Conclusion}


In the present study, the covariates affecting the health service utilization were identified. The households with health insurance significantly increased their use of health services. This study also found that the use of health services in groups of district 1, 2,3 with health insurance used health services compared to those located in Rusizi District.

There is a need for the government of Rwanda to verify the triggers of these decreases of the use of health services in latter districts. The findings of this research contributes to the existing knowledge on the effect of health insurance on health care utilization in Rwanda at household level and complements existing research by analyzing the covariates that influence most the use of health care services in Rwanda.

Authors' contributions : Roger Muremyi contributed to the design of the manuscript, data analysis and interpretation of the results; Dominique Haughton contributed in the revision of the methodology used in the data analysis and guidance in writing this manuscript; François Niragire provided constructive and valuable comments on this manuscript and made substantial revisions to the initial draft, Ignace Kabano contributed in the format and grammatical analysis. All the authors have read and agreed to the final manuscript.

Funding: No funding

Institutional Review Board Statement: Not applicable

Informed Consent Statement: Not applicable

Data Availability Statement: The data presented in this study are available on request from the corresponding author.

Conflicts of Interest: The authors declare no conflict of interest. The funders had no role in the design of the study; in the collection, analyses, or interpretation of data; in the writing of the manuscript, or in the decision to publish the results.

\section{References}

1. African strategies for health: health insurance profile. Rwanda. 2016.

2. Aimable Twahirwa. Sharing the burden of sickness: mutual health insurance in Rwanda. Bull World Health Organ. 2008 Nov;86(11):823-4. PubMed | Google Scholar

3. Ataguba JE, McIntyre D. Paying for and receiving benefits from health services in South Africa: is the health system equitable. Health Policy Plan. 2012 Mar;27 Suppl 1:i35-45. PubMed | Google Scholar 
4. Andersen R. Revisiting the behavioral model and access to care: does it matter. Journal of health and social behavior. 1995 Mar;36(1):1-10. PubMed

5. Arpah Abu-Bakara SS. The effect of health insurance on health care utilization: evidence from Malaysia. European Proceedings of Social and Behavioural Sciences. 2016;366-367. Google Scholar

6. Bounkham Vieng. The prospect of universal health coverage and equity access to health care services in Lao PDR. Cinii. 2017. Google Scholar

7. Cheng SH, Chiang TL. Disparity of medical care utilization among different health insurance schemes in Taiwan. Social Science Medicine. Soc Sci Med. 1998 Sep;47(5):613-20. PubMed | Google

\section{Scholar}

8. Grossman M. On the concept of health capital and the demand for health. Journal of Political Economy. 1972;80(2). PubMed | Google Scholar

9. Gujarati DN, Porter DC. Essentials of econometrics (McGraw-Hil International Editions) (second edition). 1999. Google Scholar

10. FS. Health insurance profile: Rwanda. 2016. Google Scholar

11. MOH. Rwanda national health insurance polcy. MOH. 2010.

12. MS. Rwanda improves access to care and equity through community-based health insurance. 2016.

13. Hidayat B, Pokhrel S. The selection of an appropriate count data model for modelling health insurance and health care demand: case of Indonesia. Int J Environ Res Public Health. 2010 Jan;7(1):9-27. PubMed | Google Scholar

14. Odeyemi IAO. Community-based health insurance programmes and the national health insurance scheme of Nigeria: challenges to uptake and integration. International Journal for Equity in Health. 2014;13:20. PubMed | Google Scholar

15. Hopkins K. Basic statistcs for the Behavioral Sciences. 1996. Google Scholar

16. John Ele-Ojo Ataguba, Jane Goudgeb. The impact of health insurance on health-care utilisation and out-of-pocket payments in South Africa. The Geneva Papers on Risk and Insurance. 2012. Google Scholar

17. Manning WG. Health insurance and the demand for medical care: evidence from a randomized experiment; American Economic Review. Am Econ Rev. 1987 Jun;77(3):251-77. PubMed | Google 
18. Maximillian Kolbe Domapielle. Health insurance and access to health care services in developing countries. Indonesian Journal of Government and Politics. 2014. Google Scholar

19. Michael Anderson, Carlos Dobkin, Tal Gross. The effect of health insurance coverage on the use of medical service. American Economic Journal. 2012;4(1). Google Scholar

20. MOH. Mutual health insurance policy in Rwanda. 2004. Google Scholar

21. RSSB. Rwanda national health insurance policy. 2019. Google Scholar

22. Ruhara Mulindabigwi Charles, Urbanus Mutuku Kioko. Effect of Health Insurance on demand for outpatient medical care in Rwanda: an application of the control function approach. Rwanda Journal. 2016. Google Scholar

23. Priyanka Saksena, Adélio Fernandes Antunes, Ke Xu, Laurent Musango, Guy Carrin. Impact of mutual health insurance on access to health care and financial risk protection in Rwanda World Health Report. World Health Organization. 2010. Google Scholar

24. WHO. World Health Organization statistical information system: core health indicators. 2006. Google Scholar

25. Thuong NTT. Impact of health insurance on healthcare utilization patterns in Vietnam : a survey based analyis with propensity score matching methods. BMC Open 2020; 10:e040062.doi:10.1136/bmjopen-2020-0440062.

26. G.Emmanuel Gwindon, (2014) . The impact of health insurance on health services utilization and health outcomes in vietman. Health Economics, policy and law,9,pp359-382doi:10.1017/S174413311400005X.

27. Agatuba et.al, (2012) . the impact of health insurance on health care utilization and out of pocket payments in south africa. Geneva papers (2012) 37, 633-654.doi:10.1057/gpp.2012.35

28. Sabrina Jiang, James, David Kindness. Quintiles. investopedia. 2020.

29. Roger Muremyi, Haughton Dominique, Kabano Ignace, Francois Niragire. Prediction of out-of-pocket health expenditures in Rwanda using machine learning techniques. The Pan African Medical. 2020;37:357. Google Scholar

30. Doble B., Tan M., Harris A., Lorgelly P. Modeling companion diagnostics in economic evaluations of targeted oncology therapies: Systematic review and methodological checklist. Expert Rev. Mol. Diagn. 2015;15:235-254. doi: 10.1586/14737159.2014.929499. - DOI - PubMed 
31. Human development repport office : http://hdr.undp.org/en/content/latest-human-development-index-ranking, 2020.

32. National institute of Statistics of Rwanda, Rwanda standard living condition survey, 2016

33. Rickard, J. L., Ngarambe, C., Ndayizeye, L., Smart, B., Majyambere, J. P., \& Riviello, R. (2018). Risk of Catastrophic Health Expenditure in Rwandan Surgical Patients with Peritonitis. World Journal of Surgery, 42(6), 1603 1609. https://doi.org/10.1007/s00268-017-4368-X

34. Médard Nyandekwe, Manassé Nzayirambaho, Jean Baptiste Kakoma. Universal health insurance in Rwanda: major challenges and solutions for financial sustainability case study of Rwanda community-based health insurance part I. The Pan African Medical. 2020;37:55. PubMed | Google Scholar

35. Mulaga AN,Kamndaya MS, Masangwi SJExamining the incidence of catastrophic health expenditures and its determinants using multilevel logistic regression in Malawi. PloS ONE 16(3): e0248752. https://doi.org/10.1371/ journal.pone. 0248752.

36. Lu C, Chin B, Lewandowski JL, Basinga P, Hirschhorn LR, et al. (2012) Towards Universal Health Coverage: An Evaluation of Rwanda Mutuelles in Its First Eight Years. PLoS ONE 7(6): e39282. doi:10.1371/journal.pone.0039282 